\title{
THE LOCALIZATION OF ORGANICALLY BOUND IODINE IN THE ENDOSTYLE OF AMPHIOXUS
}

\author{
By E. J. W. BARRINGTon, D.Sc. \\ Department of Zoology, The University, Nottingham
}

(Plate I and Text-fig. I)

Recent work has done much to strengthen, from a functional aspect, the classical view that the thyroid gland of vertebrates is homologous with the endostyle of the protochordates (Barrington \& Franchi, 1956a), for the presence of organically bound iodine has been detected in the latter organ, both in Ciona and in other ascidians (Barrington, 1957 and unpublished work) and in Amphioxus (Thomas, 1956). The occurrence of iodine binding in the endostyle of the ammocoete larva of the lamprey (Gorbman \& Creaser, 1942) is now known to be associated with a secretion which in certain properties resembles thyroid colloid, and may well be homologous with it (Barrington \& Franchi, 1956b). The presence of a similar secretion in the Ciona endostyle (Barrington, 1957) implies that a specialized thyroidal biosynthesis is also operative there, and that the iodine binding is functionally significant for the organism and is not a biochemical 'accident' as the binding which takes place in the scleroproteins of many invertebrates has been thought to be (Gorbman, 1955).

It is thus a matter of importance to determine the cytological basis for the iodination which occurs in the endostyle of Amphioxus. According to Thomas (1956) the dorsal glandular tract is associated with this process, a situation quite different from that found either in the ammocoete larva or Ciona, and it is the purpose of the present work to examine this matter in detail as a basis for a comparison of the functional organization of the three types of endostyle.

\section{MATERIAL AND METHODS}

The work was carried out in part at the Plymouth Laboratory of the Marine Biological Association, and in part at Nottingham, the methods being substantially similar to those used in previous work on the ammocoete and Ciona referred to above. For radioactive studies the animals were immersed at $10^{\circ} \mathrm{C}$ in sea water containing $200 \mu \mathrm{c}$ of ${ }^{131} \mathrm{I}$ per litre; this is one-tenth of the concentration used by Thomas (1956), who also immersed the animals for I 5-I $7 \mathrm{~h}$, whereas at Nottingham a period of $48 \mathrm{~h}$ has been adopted as a standard in all such experiments. Specimens were mostly fixed in Susa and in 
Bouin's fluid in sea water, and autoradiographs were prepared by the strippingfilm technique of Pelc (Pearse, 1954).

The endostyle is commonly described as a mucus-secreting organ, but the term 'mucus' is used so loosely in much zoological literature, to mean simply a viscous secretion, that it has been essential in the present work to select staining and histochemical methods which would give a more precise definition to it. The PAS reaction (counterstained with Harris's haematoxylin, followed either by metanil yellow or by tartrazine) has therefore been used (controlled by acetylation) to demonstrate the presence of I : 2-glycol groups, and toluidine blue metachromasia and the alcian blue method of Steedman (I950) to show whether or not the reacting secretion contains acid mucopolysaccharides, the importance of the latter being that they appear to be the main components of epithelial mucins (Pearse, 1954). The selectivity of the alcian blue was found to be much improved by the addition of an equal volume of I \% acetic acid to the I \% solution of the dye, as suggested by Lison (I954). The classical mucicarmine technique of Mayer, using Southgate's method of preparing the staining solution, has also been valuable, as has the Azan procedure.

There has been no serious difficulty in interpreting the results of these tests, although there has been a good deal of quantitative variation; animals, for example, which have been fixed and processed side by side, may show considerable differences in the intensity of their response to mucicarmine, even in such clearly defined cell types as the secretory cells of the gill bars. It seems probable that although on superficial inspection Amphioxus seems to survive well under laboratory conditions, there is, in fact, much variation in the physiological condition of different specimens by the time that they are fixed. In confirmation of this, it is of interest to note that Možejko (I913) concluded that variation in the extent to which the tissues of living Amphioxus were coloured by ingested carmine reflected differences in their physiological condition. It is also clear that another source of variation arises from the fact that the secretory contents of the cells, and sometimes even cytoplasm and nuclei, may be discharged from the endostylar epithelium under the stress of fixation. The present account has therefore been based on examination of a number of specimens fixed at different times under different conditions, some at Plymouth and some at Nottingham, and there is no reason to suppose that the conclusions are in any way affected by such variations.

\section{Organization of the endostyle}

\section{OBSERVATIONS}

Previous workers have entirely overlooked what, from the point of view of the interpretation of the iodination process, is the most important feature of the endostyle, and it is therefore necessary to give a brief new description of its organization (Text-fig. I; Pl. I, fig. I). 
At the base of the endostylar groove is a group of cells, here termed 'zone I', which closely resemble the correspondingly placed zone I cells of Ciona (Barrington, 1957). They possess slender and densely staining nuclei, long cilia, and a conspicuously striated cell border. This ciliation and border are characteristic of the whole of the endostylar epithelium, although their degrees of development vary greatly from zone to zone. Secretory droplets are present in zone I, and are strongly PAS-positive, the general cytoplasm also giving a

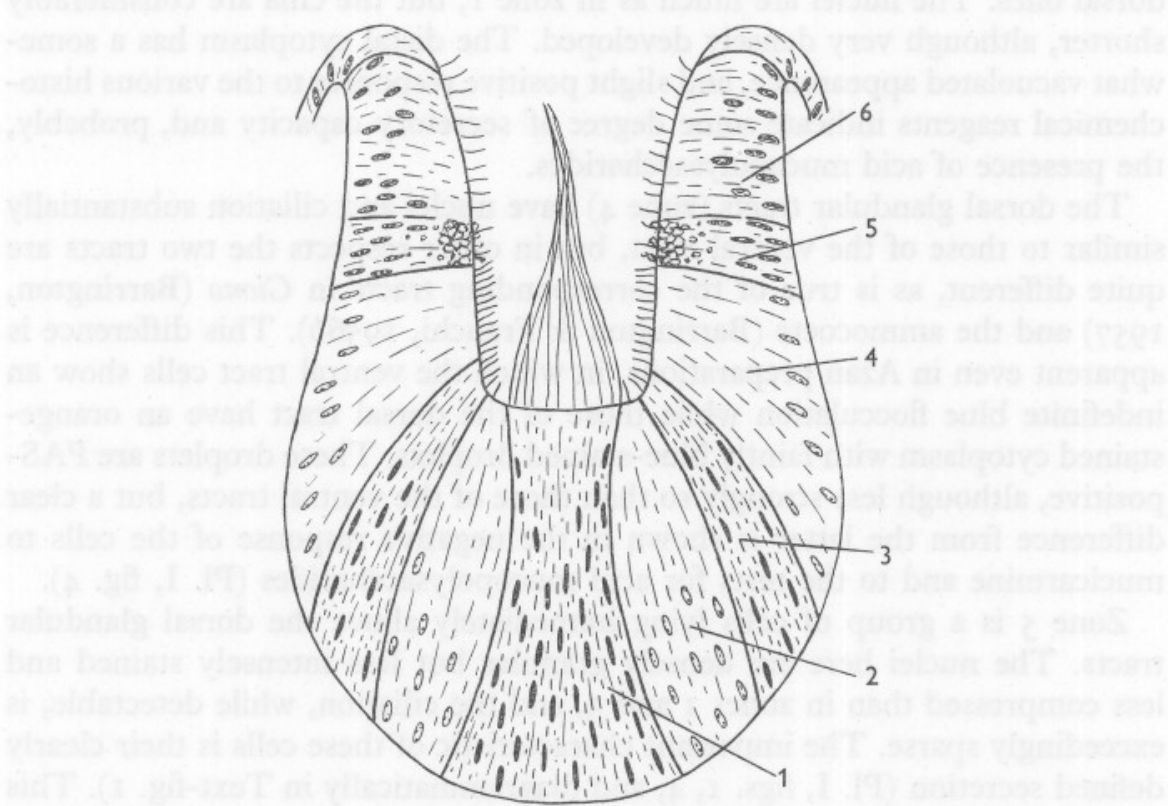

Text-fig. I. Diagrammatic transverse section across the endostylar epithelium of Amphioxus to show the distribution of the several zones, which are indicated by corresponding numbers. For further explanation see text.

positive reaction. These droplets stain with mucicarmine, and the fact that they stain selectively with alcian blue, and that toluidine blue gives a definite gamma (red) metachromasia in the cells, indicates the presence of acid mucopolysaccharides. It may thus be concluded that these cells are producing an epithelial mucin, in the sense in which the term has been used above; this secretion is particularly dense at the lateral edges of the zone (P1. I, fig. 4), from which it is discharged over the surface of the mass of long cilia, a situation which is in line with Orton's (1913) suggestion that the main function of these cilia is to deflect the endostylar secretion so that it passes out on to the lateral walls of the pharynx.

On either side of zone I lie the ventral glandular tracts (zone 2). These bear only a few cilia, while the nuclei are less densely stained than those of zone I 
and have a prominent nucleolus. PAS-positive droplets are present, and these react positively also with mucicarmine and alcian blue, while the cells show gamma metachromasia. The reactions are thus similar to those of zone $\mathrm{I}$, but they are usually less intense; it seems likely, then, that the secretion of these tracts contains acid mucopolysaccharides but that it may well differ from the secretion produced by zone $\mathrm{I}$.

Zone 3 is a narrow zone separating the ventral glandular tracts from the dorsal ones. The nuclei are much as in zone I, but the cilia are considerably shorter, although very densely developed. The distal cytoplasm has a somewhat vacuolated appearance, and slight positive responses to the various histochemical reagents indicate some degree of secretory capacity and, probably, the presence of acid mucopolysaccharides.

The dorsal glandular tracts (zone 4 ) have nuclei and ciliation substantially similar to those of the ventral tract, but in other respects the two tracts are quite different, as is true of the corresponding tracts in Ciona (Barrington, I957) and the ammocoete (Barrington \& Franchi, 1956b). This difference is apparent even in Azan preparations, in which the ventral tract cells show an indefinite blue flocculation while those of the dorsal tract have an orangestained cytoplasm with faintly blue-stained droplets. These droplets are PASpositive, although less strongly so than those of the ventral tracts, but a clear difference from the latter is shown in the negative response of the cells to mucicarmine and to the tests for acid mucopolysaccharides (Pl. I, fig. 4).

Zone 5 is a group of cells lying immediately above the dorsal glandular tracts. The nuclei here are densely granular but less intensely stained and less compressed than in zones I and 3 , and the ciliation, while detectable, is exceedingly sparse. The important characteristic of these cells is their clearly defined secretion (Pl. I, figs. I, 4, and diagrammatically in Text-fig. I). This can be seen as very fine droplets in the cytoplasm, sometimes extending down to the base of the cell, but is particularly conspicuous as an accumulation in the more distal parts, where it extends through the cell border (the striations of which are less clearly defined than elsewhere in the endostyle) and on to the occasional cilia. The extrusion of fine threads of this secretion is often evident, and there is much variation from animal to animal in the amount of secretion visible in the cell, but this is probably influenced by the factors mentioned earlier (p. II8). Such variation may, however, account for this particular region not having been previously described, for in well-fixed specimens the accumulation of secretion in these cells is impossible to overlook and, indeed, it provides the most conspicuous stainable feature of the whole endostyle. This secretion, which stains well with aniline blue in the Azan procedure, contrasts sharply with the product of the adjacent dorsal glandular tracts, for it is very strongly PAS-positive, and also reacts positively with mucicarmine and alcian blue, and shows gamma metachromasia with toluidine blue. The only other region of the endostyle which is comparable 
with it in the clarity of these reactions is the lateral edge of zone $\mathrm{I}$, and even so the reactions of zone 5 tend to be more brilliant.

Zone 6 differs from zone 5 in the much greater density of ciliation and the greater chromophilia of the nuclei. Very small PAS-positive droplets may be visible distally and may indicate, as in zone 3 , a rudimentary secretory capacity. Zone 5 , in fact, has the appearance of having been differentiated out of zone 6 by a development of its secretory capacity and a reduction of its ciliation.

The above observations lead to the conclusion that zones I and 5 are the parts of the endostyle which are most obviously mucin-secreting in the sense of producing a secretion which is rich in acid mucopolysaccharides. The latter appear also to be present in the ventral glandular tracts, and probably in zone 3 , but are certainly absent from the secretion of the dorsal glandular tracts. Here, then, as in Ciona and the ammocoete, it is evident that the endostyle is far from being a simple 'mucus-secreting' organ, and that much remains to be learned as to the nature and functions of its secretions.

\section{Autoradiographs}

Transverse sections (Pl. I, fig. 2) clearly show that bound iodine is restricted in the endostyle to two areas, lying one on each side immediately above the dorsal ciliated tracts, and that these areas correspond precisely to the groups of cells described above as zone 5 .

Each area extends over the upper ends of the cells and also into the endostylar lumen (Pl. I, figs. 3, 5). One must assume that random scatter contributes to the peripheral part of the image, but the central point of the latter can be taken as the centre of distribution of the iodine, and this appears to be located, as far as one can judge, at about the level of the surface of the epithelium (P1. I, figs. 4, 5, and also fig. 3). In other words, it lies somewhat distal to the centre of the area which is commonly occupied by the stored secretory contents of these cells. If, then, one assumes, as seems reasonable, that it is these contents which become iodinated, it seems likely that the iodination process takes place at or very near to the cell border. The autograph image may thus represent an iodinated secretion which, at least in part, has probably been discharged from the cells and which is bound to their surface and, perhaps, to their cilia. Some secretion in process of being discharged is often visible in sections, but it is not always present, and by no means corresponds exactly in amount or shape to the iodine image. Such material, in fact, need not necessarily be iodinated, for, as mentioned above, its discharge is probably in part a consequence of contraction during fixation, and the image may well be produced largely by a substance which is not actually visible in stained sections. A precisely similar situation obtains in the endostyle of the ammocoete larva (Barrington \& Franchi, 1956b), where the secretion is difficult to identify once it has left the cells, and where a clearly defined iodine image 
overlies cilia which have little, if any, visible secretion associated with them.

It follows from the above that the iodinated secretion is normally discharged into the lumen of the pharynx, and this is confirmed by the existence of radioiodine images in the lumen adjacent to the endostylar cells. Such are also to be found in the food cord in the dorsal groove, into which, as is well known, material secreted by the endostyle and gill bars is swept in consequence of the action of the pharyngeal ciliation, while the food cords in the mid-gut and intestine also give strong images. It is always to be remembered that food organisms themselves may bind iodine and contribute to such images (Barrington, 1957), but it seems wholly improbable that this could account for all of the latter; I agree, therefore, with Thomas (I956), who noted similar images in his own preparations, that the iodinated secretion of the endostyle is ultimately incorporated into the food cords.

Thomas noted that the amount of iodine taken up by Amphioxus increased to reach a maximum in about 7-Io days after they were caught. My own preparations were obtained from animals of which some were fixed at Plymouth within 5 days of being caught, while others were fixed at Nottingham, 3-4 weeks after being brought into the Plymouth Laboratory. All gave essentially similar autoradiographs. In none of them was there any certain sign of organically-bound iodine in any other part of the endostyle, such slight spots as were visible being indistinguishable from random scatter and background fogging. The absence of iodine from the lateral edges of zone I, where there are usually distinctive masses of secretion which are histochemically similar to those of the thyroidal cells, is particularly striking (P1. I, figs. 3, 5). One is driven to conclude, then, that iodine binding in this endostyle, as in that of Ciona, is not a generalized or random process, but is a specialized property of a specific group of cells.

\section{DISCUSSION}

The facts described here bring the iodine-binding activities of the endostyle of Amphioxus into closer line with those of Ciona and the ammocoete than was apparent from Thomas's account. He described the images as being 'situated near the periphery of and slightly lateral to the lateral series of mucous glands', with which I would agree, although I should not myself use the term 'mucous' (see below). Further on, however, he says that 'the most obvious centre of radioactivity in ${ }^{131} \mathrm{I}$-treated animals is in the mucus of the lateral mucous glands'. Of this my own preparations give no evidence. On the contrary, the present account defines the iodine binding as a property of a specialized group of mucus-secreting cells lying immediately above (lateral to) the lateral glandular tracts, and it is important to bear in mind that these tracts, the lateral mucous glands of Thomas's description, do not secrete mucus at all in the sense of a substance rich in acid mucopolysaccharides. 
This localization of function agrees very well with the situation in Ciona; in that animal there is, as compared with Amphioxus, an additional glandular tract on each side, but the region where iodination occurs lies immediately above the glandular tracts in a position which essentially corresponds with that of the iodination centre in Amphioxus. It is doubtful whether any significant iodination occurs in the tracts of Ciona, and it is certain that none does so in those of the ammocoete. Iodination extends over a much wider area of the endostylar epithelium of the latter than it does in the protochordates, but the regions chiefly concerned bear essentially the same relationship to the glandular tracts as do the iodination centres in Amphioxus and Ciona, allowing, of course, for the much greater complexity of the organ in the ammocoete.

In view of this fundamental morphological similarity, it is all the more interesting to find from the present work that there is a significant difference in certain histochemical properties of the iodinated material. Evidence has already been given that in the ammocoete larva (Barrington \& Franchi, $1956 b$ ) this material resembles thyroid colloid in showing, as far as these histochemical procedures go, the characteristic properties of a glycoprotein (or mucoprotein, since the two are not distinguishable by these methods). Renewed tests, in conjunction with the present work, have confirmed that this ammocoete secretion, like mammalian thyroid colloid, is negative to mucicarmine and alcian blue, and that it does not exhibit gamma metachromasia, and it may be added that the same appears to be true of Ciona, although the ascidians need much more extended study before this statement can be regarded as sufficiently broadly grounded. In Amphioxus, on the contrary, the secretion includes an acid mucopolysaccharide component, and in this respect resembles typical epithelial mucins, including those of certain other parts of the endostyle and of parts of the gill bars and dorsal groove of the pharynx. This appears, in fact, to be the first reported case of the association of iodine binding with an epithelial mucin, characterized as such by its localization and its histochemical properties.

In this connexion Thomas (1956) has suggested from his own work on Amphioxus that thyroid colloid 'is the direct evolutionary successor to the endostylar mucus of a protochordate ancestor'. The present results confirm and clarify this suggestion, but it is very important to appreciate that they show that iodine-binding in Amphioxus is not a generalized binding to all endostylar mucus. None is associated with the secretion of zone I, the acid mucopolysaccharide properties of which are indistinguishable from those of the thyroidal region of zone 5, and this means that in Amphioxus, just as in Ciona (Barrington, 1957), iodine-binding is a specialized biochemical property of a particular group of cells. This conclusion carries the implication that the product is not the result of random iodination, but that it is of biochemical significance to the organism. As Thomas (1956) points out, the work of 
Sembrat (1953) gives some reason for supposing that this product can be regarded as resembling thyroid hormone. It seems quite possible, then, from the situation in Amphioxus, as it does from that in Ciona (Barrington, I957), that the production of thyroid hormone may already be established at the protochordate level of chordate evolution but that it is passed into the lumen of the pharynx instead of being secreted directly into the blood stream. It may well be, as suggested by Thomas's work, that it is then taken up into the body through the epithelium of the alimentary canal as part of the normal process of digestion and absorption of food, but it is hoped to report further on this aspect in a later publication.

I am much indebted to the Director and Staff of the Plymouth Laboratory for the trouble taken to provide me with the animals and facilities needed for this work, to Mr T. Berbank for taking the photomicrographs, and to Miss J. Plumtree for technical assistance.

\section{SUMMARY}

An account is given of some features of the organization of the endostyle of Amphioxus, with particular reference to the distribution of sites of mucus secretion as indicated by positive responses to tests for acid mucopolysaccharides. Autoradiography shows that the centre of distribution of organically-bound iodine is associated with the tips of the mucus-secreting cells of zone 5, and not with the glandular tracts. Mucus secretion also occurs elsewhere in the endostyle (although not in the dorsal glandular tracts), but as it is not associated with any accumulation of bound iodine it is concluded that the binding in zone 5 is a specialized property of the cells of that particular zone. The results are discussed in the light of recent work on the protochordates and the ammocoete larva, and it is concluded that in Amphioxus, as in the Tunicata, there is reason for supposing that the iodination process is a biochemical specialization and that its product must therefore be of some physiological significance to the organism. Attention is also drawn to the evolutionary interest of the association of iodine-binding with a mucin rather than with a glycoprotein.

\section{REFERENCES}

BARRINGTON, E. J. W., I957. The distribution and significance of organically bound iodine in the ascidian Ciona intestinalis Linnaeus. F. mar. biol. Ass. U.K., Vol. 36, pp. I-I5.

Barrington, E. J. W. \& Franchi, L. L., I956a. Organic binding of iodine in the endostyle of Ciona intestinalis. Nature, Lond., Vol. 177, p. 432.

- 1956b. Some cytological characteristics of thyroidal function in the endostyle of the ammocoete larva. Quart. F. micr. Sci., Vol. 97, pp. 393-4I0.

GoRBMAN, A., I955. Some aspects of the comparative biochemistry of iodine utilization and the evolution of thyroidal function. Physiol. Rev., Vol. 35, pp. 336-46. 

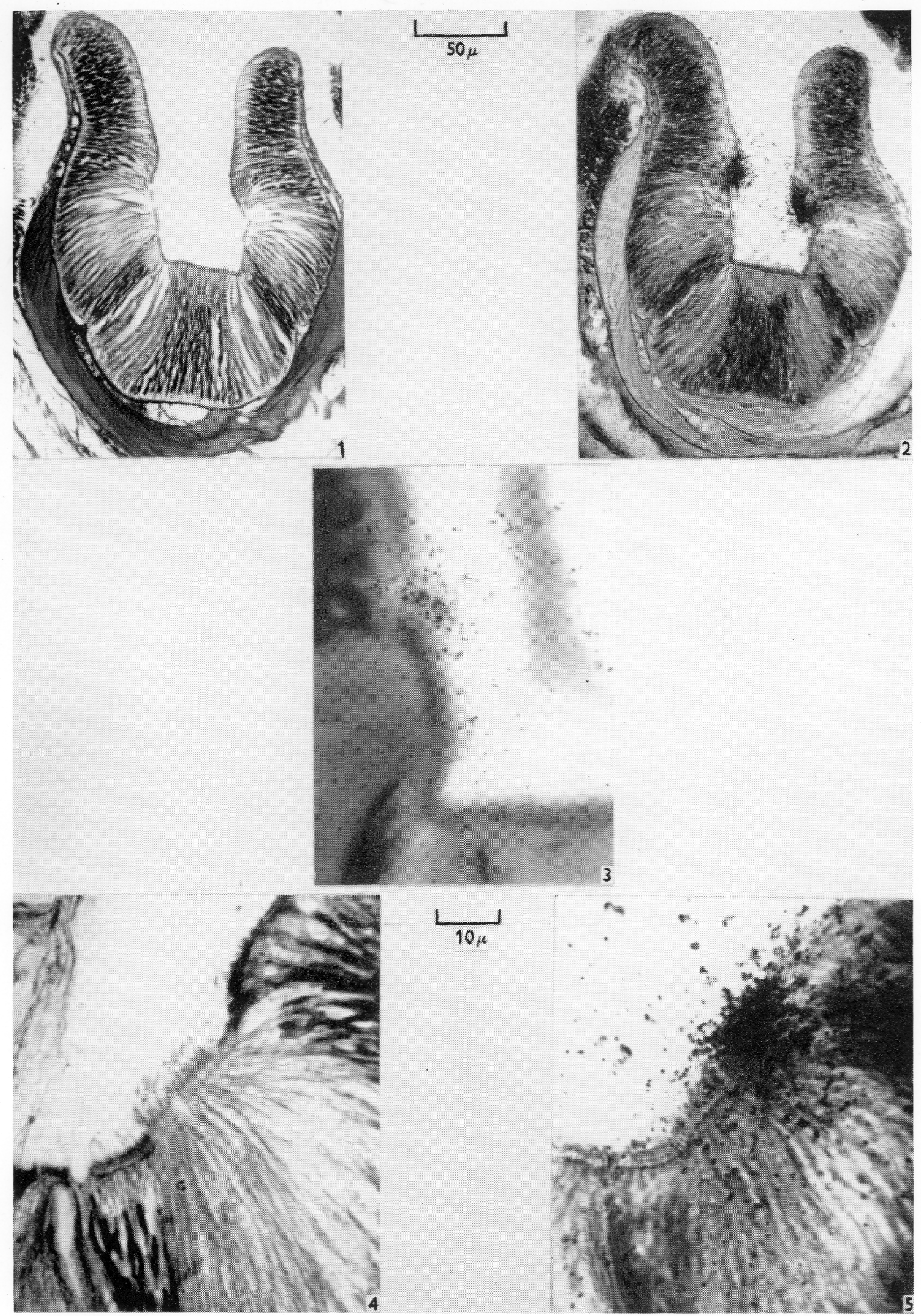
Gorbman, A. \& CREASER, C. W., I942. Accumulation of radio-active iodine by the endostyle of larval lampreys and the problem of homology of the thyroid. F. exp. Zool., Vol. 89, pp. 39I-406.

Lison, L., I954. Alcian blue $8 \mathrm{G}$ with chlorantine fast red $5 \mathrm{~B}$. A technic for selective staining of mucopolysaccharides. Stain Tech., Vol. 29, pp. I3I-8.

MožEJKo, B., I913. Mikrotechnische Mitteilungen. X. Karminfütterung des Amphioxus. Z. wiss. Mikr., Bd. 30, pp. 59-67.

Orton, J. H., I913. The ciliary mechanisms of the gill and the mode of feeding in Amphioxus, ascidians and Solenomya togata. F. mar. biol. Ass. U.K., Vol. Io, pp. 19-49.

PeArSe, A. G. E., 1954. Histochemistry, Theoretical and Applied. London: Churchill.

SEMBrat, K., I953. Effect of the endostyle of the lancelet (Branchiostoma lanceolatus Pall.) on the metamorphosis of axolotl. Zool. Polon., Vol. 6, pp. 3-19.

SteEDMAN, H. F., I950. Alcian blue 8GS: A new stain for mucin. Quart. F. micr. Sci., Vol. 9I, pp. 477-9.

Thомаs, I. M., I956. The accumulation of radioactive iodine by Amphioxus. F. mar. biol. Ass. U.K., Vol. 35, pp. 203-Io.

\section{EXPLANATION OF PLATE I}

Fig. I. Transverse section of the endostyle of Amphioxus, which should be compared with Text-fig. I for the identification of the several zones. Zones 2 and 4 (ventral and dorsal glandular tracts) can be distinguished by the lighter staining and more basal location of their nuclei. The PAS-positive secretion (slightly darker) at the distal ends of the zone 5 cells is clearly visible on the right side of the endostyle at the point where the epithelium swells slightly to the left. PAS, Harris's haematoxylin and tartrazine.

Fig. 2. Autoradiograph of a section adjacent to that of fig. I. The black iodine image is centred over the tips of the zone 5 cells.

Fig. 3. Autoradiograph of a transverse section of the left side of an endostyle. Zone 3, with dark nuclei, lies at the right-angled bend; zones 2 and $\mathrm{r}$ lie to its right, while zone 4 (dorsal glandular tract) lies above it. Zone 5 lies immediately above zone 4 and continues into zone 6 . An unusually light iodine image has been obtained as a result of the use of a slightly over-age stripping-film, and is clearly seen to extend into the lumen from the tips of the zone 5 cells; the small amount of secretion accumulated at the distal ends of these is represented by a negative image. Note the absence of any iodine image over the mucus-secreting cells of zone I, which lie at the bottom right-hand corner; the background of scattered spots is a result of fogging.

Fig. 4. Transverse section of the right side of an endostyle, stained with alcian blue (Harris's haematoxylin as counterstain). Zone 4 (dorsal glandular tract) is the light area occupying the middle of the region photographed, and is completely negative. A strong positive response is seen in the distal ends of the zone 5 cells, lying immediately above zone 4 ; a weaker reaction is just detectable in zones 3 and 2, but a strong one is shown at the right edge of zone $I$, which just comes into view at the extreme left margin.

Fig. 5. Autoradiograph of a section adjacent to that of Fig. 4. The centre of the dense black iodine image overlies the tips of the zone 5 cells, the position of which can be gauged by comparison with Fig. 4. Note the complete absence of iodine accumulation elsewhere, even over the edge of zone I, despite the positive alcian blue (mucin) response which this shows in Fig. 4 . 